\title{
Liver Resection in a Tertiary University Hospital in Damascus- trends Related to the Political Strife and Social Crisis
}

\author{
Basel Ahmad ${ }^{1}$, Mohamad Essam Marwa ${ }^{1}$, Khaled Turkmani', Tareq Ahmad', \\ Ramez Baghdadi', Shaimaa Aboudamaah ${ }^{1}$, Khetam Alkhatib ${ }^{2}$, Mohamad Ahmad ${ }^{3}$
}

${ }^{1}$ Damascus University, Faculty of Medicine, Syrian Arab Republic. ${ }^{2}$ Department of Internal Medicine, Al_Mouasat University Hospital, Damascus University Faculty of Medicine, Syrian Arab Republic. ${ }^{3}$ Professor of Surgery, Head of Surgery Department, Faculty of Medicine, Damascus University, Chief of Liver Transplant Team, Al Assad University Hospital, Damascus.

\begin{abstract}
Background: Liver resection is a major operation requires technical training and experience and is expensive for the health care system. Aim: Our aim was to review trends in liver resection in Syria to help our country and others like Syria to understand the hardships for the country's health care policy. Methods: We analyzed retrospectively the results of 95 patients who underwent a liver resection from January 2009 through December 2015 at our tertiary university hospital in Damascus. Results: The number of annual liver resections increased over this 6 year period, but there were several years during which the numbers were dramatically less, related to the social crisis. Of them, 63 underwent resection for malignant neoplasms (66\%) and 30 for non-malignant disorders (32\%). Conclusion: Dedication of our surgeons to hepatic surgery is increasing in Syria with mortality rates close to international standards despite the ongoing social unrest and political strife.
\end{abstract}

Keywords: Liver resection- hepatectomy-social crisis- Damascus- Syria

Asian Pac J Cancer Care, 5 (2), 79-82

\section{Introduction}

Liver resection is the most efficacious treatment for patients with hepatic malignancies and selected benign diseases [1,2-3]. Improvements in various aspects of hepatic resections have led to better outcomes in recent decades. Our better comprehension of liver segmental anatomy improved assessment of appropriate candidates for such a major operation, and, immense progress in techniques of resection are important factors that have made liver resection a more common and safer operation [4]. The improved selection of patients and advances in perioperative management have decreased markedly the early postoperative mortality from $13 \%$ for all resections and $>20 \%$ for major resections to less than $8 \%$ [5].

Over the recent several decades, evidence has shown that operative resection of hepatic metastases can be undertaken safely in the majority of patients with resectable disease. This is especially true for patients
Submission Date: 02/20/2020Ａcceptance Date: 05/04/2020 suffering from colorectal liver metastases [6,7-8-9] patients with other neoplasms metastatic to the liver are potential candidates, but the outcomes are not as well documented.

Most prior studies of the results and frequency of liver resections have come mainly from European countries and East Asia with few studies from Middle-East countries.

The aim of our study was to evaluate our 7-year experience in a major tertiary referral hospital in Syria with liver resections, mainly the indications, perioperative features, and pathologic findings in order to detail risk factors and mortality of hepatectomy in the setting of political unrest and social crisis.

\section{Materials and Methods}

All patients who underwent liver resection At Al Assad University Hospital in Damascus, Syria between 1/1/2009

Corresponding Author:

Dr. Basel Ahmad

Damascus University, Faculty of Medicine, Syrian Arab Republic.

Email: dr.baselahmad@gmail.com 
and 31/12/2015 were evaluated for inclusion in this study. Patients who had not resectable disease or had undergone radiofrequency ablation were excluded.

Standard demographic and clinic data were obtained, including age, sex, place of residency, blood group, pathology, history of smoking or alcohol use, history of diabetes or hypertension, days in Intensive Care Unit and postoperative hospitalization.

On presentation, all patients underwent a full history and physical examination, ultrasonography, and a multi-slice computed tomography; Magnetic resonance imaging was not available all the time. The decision to give neoadjuvant chemotherapy was made on a case by case basis according to the expected beneficial results. Resections were undertaken by the same operative technique and performed under maintenance of a low central venous pressure. Our operative team performed only open resections with the use of a Pringle maneuver and intraoperative ultrasonography used at the discretion of the surgeon. The hepatic parenchyma was divided by the clamp-crush technique or with the use of an energy-assisted device. The condition of the patient postoperatively was used to determine whether the patient needed ICU care or could be managed on the surgical floor.

Descriptive analyses were performed using IBM SPSS statistic version 23, and the missing data were excluded from analysis. This study was approved by the Research Ethics Committee, Faculty of Medicine, Damascus University (decision number 16-02-07).

\section{Results}

Between January 2009 and December 2015, 95 patients underwent a hepatic resection, including 43 male $(45 \%)$ and 52 females $(55 \%)$. The median age was 50 (range, 9-74) years; there were 4 patients less than 20 years old and one child less than 10 years old (Figure 1). Smoking habits were present in 22 patients (23\%). 4 smokers (18\%) had malignant neoplasms. Alcohol consumption was present in 6 patients $(6 \%), 2$ of whom had malignant neoplasms. Other co-morbidities

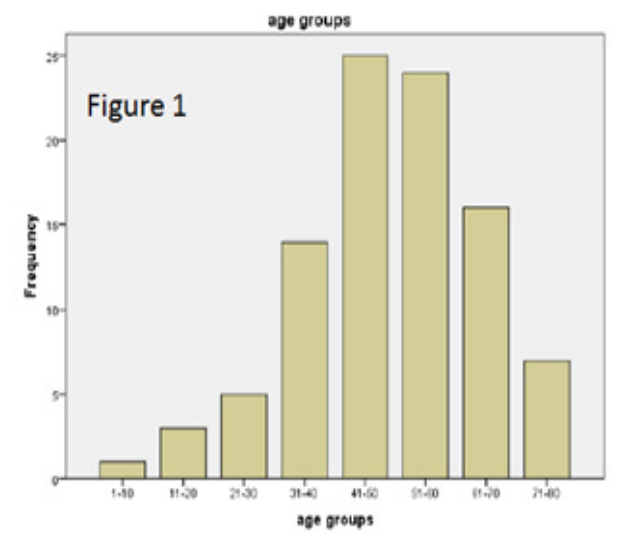

Figure 1. Age Distribution of the Patients Undergoing Hepatic Resection
Table 1. Type of Hepatic Resection

\begin{tabular}{lcc}
\hline Type of Liver resection & $\mathrm{N}$ & Percentage \\
\hline Nonanatomic segmental resections & & \\
$\quad$ Single & 19 & $20 \%$ \\
Two & 12 & $12.6 \%$ \\
Three & 1 & $1.1 \%$ \\
Four & 1 & $1.1 \%$ \\
Anatomic & & \\
S2-3 & 5 & $5.3 \%$ \\
S6-7 & 8 & $8.4 \%$ \\
Anatomic right hemiepatectomy & 19 & $20 \%$ \\
Anatomic left hemiepatectomy & 17 & $17.9 \%$ \\
Anatomic extended right hepatectomy & 5 & $5.3 \%$ \\
Anatomic extended left hepatectomy & 8 & $8.4 \%$ \\
\hline
\end{tabular}

included diabetes mellitus in 14 patients and hypertension was in 18 .

In 2009 , we performed only 10 hepatic resections. But in the years to follow, 2010 through 2015, we performed annually $17,6,12,16,13$, and most recently in 2016, 21 hepatic resections, respectively. The median duration of stay in the hospital was 11 days, while the median duration of stay in the ICU for the 76 patients who required ICU care was 3 days.

Of 95 patients, 61 had anatomic resection (64\%) and 34 had non-anatomic resection (36\%). Table 1 shows the types of resection. There were 63 patients who underwent hepatic resection for malignant neoplasms $(66 \%)$ and 30 for non-malignant tumors (32\%). Seven patients died during operation or within days of hospitalization. The mean number of units of blood, plasma, and platelets used during the operation and hospitalization was 3.3, $3.2,0.6$ units, respectively; 13 patients never requited any blood products.

\section{Discussion}

Hepatic resection is now firmly established as the most effective treatment for patients with primary hepatobiliary malignancies, selected patients with certain extrahepatic malignant neoplasms metastatic to the liver, and some benign disorders involving the liver [10-11].

Smoking is considered one of the most important risk factors for the development of early complications after partial hepatectomy. We have closely smokers' ratio to others studies. Alcohol is one of the Common causes of existing liver disease but we have low value compared to other studies, this could be due to our traditions [12-13].

The annual number of formal liver resections has increased since 2009. But as seen, this increase was disrupted from 2011 through 2014 during the especially difficult times for our country. Our ongoing civil war has disrupted the ready ability to refer patients to our university hospital. Despite these hardships, we have worked hard to provide the services needed to those who could find the way to present at our university hospital. Much of what we have been able to accomplish is related 
to the unwavering dedication of our medical personnel whose goal is to provide the best care possible to our citizens.

Patients with greater levels of postoperative pain tend to have more complications after surgery, longer hospitalization leading to higher medical costs, and lower levels of patient satisfaction [14]. The duration of hospitalization may not reflect surgeon/institution performance, because in these times of strife, the appropriate time for discharge is multifactorial and likely related to the population, patient selection, and increased high-risk cases with a surgeon's experience [15]. In this study, we achieved close and reasonable ratio to the rest of the studies [16,17-18].

In our study, we also have identified the geographic distribution of residential areas subject to the liver and found that Damascus and its countryside is the most frequent place of residency of patients, not to forget that the main liver surgery center in Syria is in the hospital of our study in Damascus.

Consumption of banked blood may reflect the degree of blood loss [19-20]. However, the mainstay to prevent bleeding is crucial during hepatectomy [21-20]. Our mean blood unit and plasma unit is less than some other studies [22].

The functional residual hepatic reserve must be considered for any liver resection [23]. This has been of course one of our considerations in doing any formal hepatic resections and post-surgery hepatic failure and deterioration in liver function were studied in our previous paper [3]. In addition, surgical stress can be decreased by non-anatomic resections when appropriate, which may affect perioperative morbidity and mortality [24-25]. Several studies reported shorter operating times and significantly less blood loss after non anatomic resections [26-27]. Thus we have tried to use these non-anatomic resections when appropriate, especially for metastatic lesions and for non-malignant conditions.

Laparoscopic resection is now carried on some countries showing similar results to open technique but unfortunately it is still not carried on in Syria due to lack of appropriate laparoscopic equipment and experience. However, Dedication of our surgeons to hepatic surgery may lead to perform this in the near future just like (the liver transplantation team in AlAssad university hospital in Damascus) performed the first liver transplantation in Syria in the beginning of 2016.

In our series, there were seven deaths during operation or hospitalization: four in the Anatomic resection group, and three in the non-anatomic resection group, which was not significantly different. There are studies suggesting more postoperative deaths After an anatomic resection [27-28].

In conclusion, liver resection surgery is still being performd and appears to be increasing in Syria despite the political and social unrest in our country. With the dedication and hard work of our health care providers, we have been able to provide the expertise needed to accomplish relativelysafe and successful liver resections with morbiditiy and mortality rates close to the rates described elsewhere in the world.

Conflict of interest

There is nothing to disclose.

\section{References}

1. Imamura H, Seyama Y, Kokudo N, Maema A, Sugawara Y, Sano K, et al. One thousand fifty-six hepatectomies without mortality in 8 years. Arch Surg 2003;138(11):1198-206; discussion 1206.

2. Charny CK, Jarnagin WR, Schwartz LH, Frommeyer HS, DeMatteo RP, Fong Y, et al. Management of 155 patients with benign liver tumours. Br J Surg 2001;88(6):808-13.

3. Ahmad B, Turkmani K, Marwa ME, Ahmad T, Baghdadi R, Aboudamaah S, et al. Perioperative Liver Function after Hepatectomy in a Tertiary University Hospital in Damascus. Asian Pac J Cancer Prev 2017;18(8):2109-2113.

4. Sugarbaker PH. Surgical decision making for large bowel cancer metastatic to the liver. Radiology 1990;174(3):621626.

5. Belghiti J, Regimbeau JM, Durand F, Kianmanesh AR, Dondero F, Terris B, et al. Resection of hepatocellular carcinoma: a European experience on 328 cases. Hepatogastroenterology;49(43):41-6.

6. Simmonds PC, Primrose JN, Colquitt JL, Garden OJ, Poston GJ, Rees M. Surgical resection of hepatic metastases from colorectal cancer: A systematic review of published studies. Br J Cancer 2006;94(7):982-999.

7. Wei AC, Greig PD, Grant D, Taylor B, Langer B, Gallinger S. Survival After Hepatic Resection for Colorectal Metastases: A 10-Year Experience. Ann Surg Oncol 2006;13(5):668-676.

8. Leporrier J, Maurel J, Chiche L, Bara S, Segol P, Launoy G. A population-based study of the incidence, management and prognosis of hepatic metastases from colorectal cancer. $\mathrm{Br}$ J Surg 2006;93(4):465-474.

9. Sjövall A, Järv V, Blomqvist L, Singnomklao T, Cedermark B, Glimelius B, et al. The potential for improved outcome in patients with hepatic metastases from colon cancer: a population-based study. Eur J Surg Oncol 2004;30(8):83441.

10. Agrawal S, Belghiti J. Oncologic Resection for Malignant Tumors of the Liver. Ann Surg 2011;253(4):656-665.

11. Bruix J, Sherman M, American Association for the Study of Liver Diseases. Management of hepatocellular carcinoma: An update. Hepatology 2011;53(3):1020-1022.

12. Lv Y, Liu C, Wei T, Zhang J-F, Liu X-M, Zhang X-F. Cigarette smoking increases risk of early morbidity after hepatic resection in patients with hepatocellular carcinoma. Eur J Surg Oncol 2015;41(4):513-9.

13. Park SK, Jung YK, Chung DH, Kim KK, Park YH, Lee JN, et al. Factors influencing hepatocellular carcinoma prognosis after hepatectomy: a single-center experience. Korean J Intern Med 2013;28(4):428.

14. Joshi GP, Ogunnaike BO. Consequences of Inadequate Postoperative Pain Relief and Chronic Persistent Postoperative Pain. Anesthesiol Clin North America 2005;23(1):21-36.

15. Lorenzo CSF, LIMM WML, Lurie F, Wong LL. Factors affecting outcome in liver resection. HPB 2005;7(3):226230.

16. Wang H-Q, Yang J, Yan L-N, Zhang X-W, Yang J-Y. Liver resection in hepatitis $\mathrm{B}$ related-hepatocellular carcinoma: clinical outcomes and safety in elderly patients. World J Gastroenterol 2014;20(21):6620-5. 
17. Jarnagin WR, Gonen M, Fong Y, DeMatteo RP, Ben-Porat $\mathrm{L}$, Little $\mathrm{S}$, et al. Improvement in perioperative outcome after hepatic resection: analysis of 1,803 consecutive cases over the past decade. Ann Surg 2002;236(4):397-406; discussion 406-7.

18. Moss CR, Caldwell JC, Afilaka B, Iskandarani K, Chinchilli VM, McQuillan P, et al. Hepatic resection is associated with reduced postoperative opioid requirement. J Anaesthesiol Clin Pharmacol 2016;32(3):307-13.

19. Yuasa T, Niwa N, Kimura S, Tsuji H, Yurugi K, Egawa H, et al. Intraoperative blood loss during living donor liver transplantation: an analysis of 635 recipients at a single center. Transfusion 2005;45(6):879-84.

20. Devi A. Transfusion practice in orthotopic liver transplantation. Indian J Crit Care Med 2009;13(3):120.

21. Mor E, Jennings L, Gonwa TA, Holman MJ, Gibbs J, Solomon $\mathrm{H}$, et al. The impact of operative bleeding on outcome in transplantation of the liver. Surg Gynecol Obstet 1993;176(3):219-27.

22. Kaibori M, Saito T, Matsui K, Yamaoka M, Kamiyama Y. Impact of fresh frozen plasma on hepatectomy for hepatocellular carcinoma. Anticancer Res;28(3B):1749-55.

23. Adam R, Wicherts DA, de Haas RJ, Ciacio O, Lévi F, Paule $\mathrm{B}$, et al. Patients with initially unresectable colorectal liver metastases: is there a possibility of cure? J Clin Oncol 2009;27(11):1829-35.

24. Gold JS, Are C, Kornprat P, Jarnagin WR, Gönen M, Fong $\mathrm{Y}$, et al. Increased use of parenchymal-sparing surgery for bilateral liver metastases from colorectal cancer is associated with improved mortality without change in oncologic outcome: trends in treatment over time in 440 patients. Ann Surg 2008;247(1):109-17.

25. Kokudo N, Tada K, Seki M, Ohta H, Azekura K, Ueno M, et al. Anatomical major resection versus nonanatomical limited resection for liver metastases from colorectal carcinoma. Am J Surg 2001;181(2):153-9.

26. Finch RJB, Malik HZ, Hamady ZZR, Al-Mukhtar A, Adair $R$, Prasad KR, et al. Effect of type of resection on outcome of hepatic resection for colorectal metastases. Br J Surg 2007;94(10):1242-8.

27. Stewart GD, O’Súilleabháin CB, Madhavan KK, Wigmore SJ, Parks RW, Garden OJ. The extent of resection influences outcome following hepatectomy for colorectal liver metastases. Eur J Surg Oncol 2004;30(4):370-6.

28. Zorzi D, Mullen JT, Abdalla EK, Pawlik TM, Andres A, Muratore A, et al. Comparison between hepatic wedge resection and anatomic resection for colorectal liver metastases. J Gastrointest Surg 2006;10(1):86-94.

This work is licensed under a Creative Commons AttributionNon Commercial 4.0 International License. 